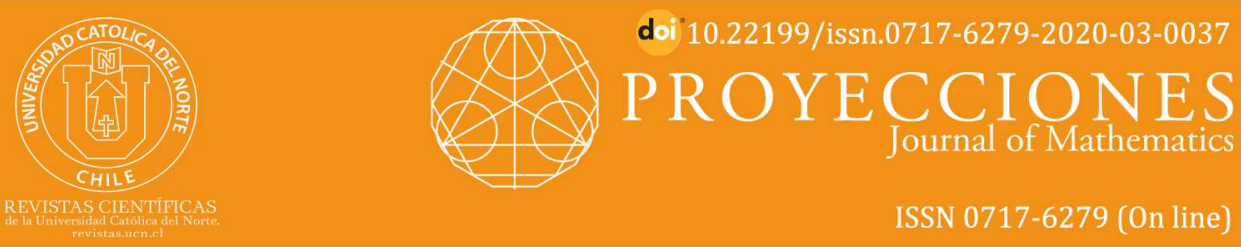

\title{
Convergence analysis for combination of equilibrium problems and $k$-nonspreading set-valued mappings
}

\author{
Suhel Ahmad Khan ${ }^{1}$ (1) orcid.org/0000-0002-7328-6578 \\ Kaleem Raza Kazmi²] orcid.org/0000-0002-2035-1209 \\ Watcharaporn Cholamjiak ${ }^{3}$ (1) orcid.org/0000-0002-8563-017X \\ Hemen Dutta ${ }^{4}$ (1) orcid.org/0000-0003-2765-2386 \\ ${ }^{1}$ BITS-Pilani, Dubai Campus, Dept of Mathematics, Dubai, United Arab Emirates. \\ - khan.math@gmail.com \\ ${ }^{2}$ Aligarh Muslim University, Dept. of Mathematics, Aligarh, UP, India. \\ krkazmi@gmail.com \\ ${ }^{3}$ University of Phayao, School of Science, Phayao, Thailand. \\ C-wchp007@hotmail.com \\ ${ }^{4}$ Gauhati University, Dept. of Mathematics, Guwahati, AS, India. \\ - hemen_dutta08@rediffmail.com
}

Received: May 2019 | Accepted: April 2020

\section{Abstract:}

We find a common solution of generalized equilibrium problems and the set of fixed points of a $k$-nonspreading setvalued mapping by using shrinking projection hybrid method. Finally, we compare the shrinking solution set after randomization by giving numerical example which justifies our main result.

Keywords: Shrinking projection hybrid method; Fixed point problem; $k$-nonspreading set-valued mappings.

MSC (2010): 90C33, 47H09, 49J30.

\section{Cite this article as (IEEE citation style):}

S. A. Khan, K. R. Kazmi, W. Cholamjiak and H. Dutta, "Convergen-

ce analysis for combination of equilibrium problems and $\mathrm{k}$ -

nonspreading set-valued mappings", Proyecciones (Antofagasta,

On line), vol. 39, no. 3, pp. 599-619 Jun. 2020, doi:

10.22199/issn.0717-6279-2020-03-0037.

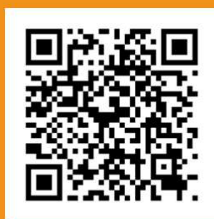

Article copyright: (C) 2020 Suhel Ahmad Khan, Kaleem Raza Kazmi, Watcharaporn Cholamjiak and Hemen Dutta. This is an open access article distributed under the terms of the Creative Commons Licence, which permits unrestricted use and distribution provided the original author and source are credited. 


\section{Introduction}

Throughout the paper, let $E$ be a closed, convex subset of real Hilbert space $H .\langle.,$.$\rangle and \|$.$\| are inner product and induced norm, respectively.$

For $M: E \times E \rightarrow \mathbf{R}$, the equilibrium problem (for short, $E P$ ) is of finding $u \in E$ such that

$$
M(u, v) \geq 0, \forall v \in E .
$$

If $\operatorname{EP}(M)$ is set of all solutions of above (1.1), then

$$
E P(M)=\{u \in E: M(u, v) \geq 0, \forall v \in E\} .
$$

Blum and Oettli [2] introduced Equilibrium problems which has helped to develop and solve many problems of game theory, economics and optimization problems. Recently many researchers studied and used its applications in many important areas, see for example $[1,2,3,4,7,8,9$, $10,12,15,17,18,19,20]$. To solve various class of equilibrium problems different useful iterative results have been introduced; see for examples $[1,2,3,4,7,9,10,12,15,17,18,19,20]$ and references therein.

Now we consider following generalized equilibrium problems: For each $i=1,2, \ldots, N$, let $M_{i}: E \times E \rightarrow \mathbf{R}$ be a bifunction and $a_{i} \in(0,1)$ with $\sum_{i=1}^{N} a_{i}=1$. Consider a mapping $\sum_{i=1}^{N} a_{i} M_{i}: E \times E \rightarrow \mathbf{R}$. The generalized equilibrium problems (for short, GEP) is of finding $u \in E$ such that

$$
\left(\sum_{i=1}^{N} a_{i} M_{i}\right)(u, v) \geq 0, \quad \forall v \in E
$$

It has been introduced by Suwannaut and Kangtunyakarn [17] and later on $G E P(1.3)$ further generalized Bnouhachem [1] and Kazmi et al. [6].

Generalized equilibrium problem $G E P(1.3)$ solutions set is denoted by $\operatorname{EP}\left(\sum_{i=1}^{N} a_{i} M_{i}\right)$, i.e.,

$$
E P\left(\sum_{i=1}^{N} a_{i} M_{i}\right)=\left\{u \in E:\left(\sum_{i=1}^{N} a_{i} M_{i}\right)(u, v) \geq 0, \forall v \in E\right\} .
$$


For each $i=1,2, \ldots, N$ we have $M_{i}=M$, above problem reduces to $E P(1.1)$.

Let the Hausdorff metric defined on the family of compact subsets $C O(E)$ is given by

$$
H(U, V)=\max \left\{\sup _{u \in U} d(u, V), \sup _{v \in V} d(v, U)\right\}, \text { for all } U, V \in C O(E),
$$

where $d(u, V)=\inf _{b \in V}\|u-b\|$. An element $p \in E$ is called a fixed point of $T: E \rightarrow E$ (resp. $T: E \rightarrow C O(E)$ ) if $p=T p$ (resp. $p \in T p$ ). $F(T)$ is the set of all fixed points of $T$.

Mann [13], in 1953, introduced and studied the iterative sequence $\left\{u_{n}\right\}$ which is given by

$$
u_{n+1}=\alpha_{n} u_{n}+\left(1-\alpha_{n}\right) T u_{n},
$$

where $u_{0} \in E$ is arbitrarily chosen and real sequence $\left\{\alpha_{n}\right\} \in[0,1]$. Mann's iterative method (1.5) is most extensively explored and successful method which is capable in constructing and handling nonexpansive mapping's fixed points. Recently, many authors extensively investigated and studied nonexpansive mappings by using various modified Mann's iterative methods. In 2003, Nakajo and Takahashi [14] studied a modified Mann's iterative method where the sequence $\left\{u_{n}\right\}$ is generated by

$$
\left\{\begin{array}{l}
u_{1} \in E \\
v_{n}=\alpha_{n} u_{n}+\left(1-\alpha_{n}\right) T u_{n} \\
E_{n}=\left\{z \in E:\left\|v_{n}-z\right\| \leq\left\|u_{n}-z\right\|\right\} \\
K_{n}=\left\{z \in E:\left\langle u_{1}-u_{n}, z-u_{n}\right\rangle \leq 0\right\} \\
u_{n+1}=P_{E_{n} \cap K_{n}} u_{1}, n \geq 1
\end{array}\right.
$$

$\left\{\alpha_{n}\right\} \subset(0,1)$. Nakajo and Takahashi shown that above sequence converges strongly to $P_{F(T)} x_{1}$, where $P_{F(T)}$ is projection of metric on $F(T)$.

For finding a common solutions of $\mathrm{EP}(1.1)$ and the set of fixed points problems, in 2007, Tada and Takahashi [19], proposed the following scheme in $H$ : Given $x_{1}=x \in H$, the sequences $\left\{x_{n}\right\}$ and $\left\{u_{n}\right\}$ generated by the scheme

$$
\left\{\begin{array}{l}
u_{n} \in E \text { such that } M\left(u_{n}, y\right)+\frac{1}{r_{n}}\left\langle y-u_{n}, u_{n}-x_{n}\right\rangle \geq 0, \quad \forall y \in E, \\
y_{n}=\alpha_{n} x_{n}+\left(1-\alpha_{n}\right) T u_{n}, \\
E_{n}=\left\{z \in H:\left\|y_{n}-z\right\| \leq\left\|x_{n}-z\right\|\right\}, \\
K_{n}=\left\{z \in H:\left\langle x_{1}-x_{n}, z-x_{n}\right\rangle \leq 0\right\}, \\
x_{n+1}=P_{E_{n} \cap K_{n}} x_{1}, n \geq 1,
\end{array}\right.
$$


$\left\{\alpha_{n}\right\} \subset(0,1)$ and $\left\{r_{n}\right\} \subset(0, \infty)$ satisfies $\liminf _{n \rightarrow \infty} r_{n}>0$. Then $\left\{x_{n}\right\}$ converges strongly to $P_{\Omega} x_{1}$, where $\Omega:=E P(G) \stackrel{n \rightarrow \infty}{\cap} F(T)$.

Kohsaka and Takahashi [11], in 2008, introduced a mapping $T: E \rightarrow E$ known as nonspreading if

$$
2\|T u-T v\|^{2} \leq\|T u-v\|^{2}+\|T v-u\|^{2}, \text { for all } u, v \in E .
$$

Inspired by Iemoto et al. [5] and Liu [12], recently, Suantai et al. [15] proposed generalized $k$-nonspreading set-valued mappings by using Hausdorff metric. $T: E \rightarrow C O(E)$ is a $k$-nonspreading set-valued mapping if for $k>0$

$$
H(T u, T v)^{2} \leq k\left(d(T u, v)^{2}+d(u, T v)^{2}\right), \text { for all } u, v \in E .
$$

We can easily observe that for all $u \in E, k \in(0,1)$ and $p \in F(T),(1.8)$ implies

$$
H(T u, T p) \leq \sqrt{\frac{k}{1-k}}\|u-p\| .
$$

In particular, if $T$ is a $\frac{1}{2}$-nonspreading and $F(T) \neq \emptyset$, then $T$ is quasinonexpansive. To find a common solution of the split equilibrium problem and the fixed point problem for a $\frac{1}{2}$-nonspreading set-valued mapping in Hilbert spaces, Suantai et al. [15] established a weak convergence result.

It is well known that strong convergence behaviour of iteration is more desirable than weak convergence, therefore in this paper, we propose shrinking projection hybrid method for finding a common solution of the set of $G E P(1.3)$, a combination of $C Q$-method and shrinking projection method and the set of fixed points of a $k$-nonspreading set-valued mapping with $k \in\left(0, \frac{1}{2}\right]$, which is more general than $\frac{1}{2}$-nonspreading set-valued mapping and we prove a strong convergence result. Finally by giving an numerical example we have verified that our proposed iterative method is more faster and effective than the results given in $[6,14,15,16,17,19]$.

\section{Preliminaries}

Now, we give some basic definitions and results before proving our main result.

Lemma 2.1 For $u, v \in H$ and $\alpha \in[0,1]$, we have: 
(i) $\|\alpha u+(1-\alpha) v\|^{2}=\alpha\|u\|^{2}+(1-\alpha)\|v\|^{2}-\alpha(1-\alpha)\|u-v\|^{2}$;

(ii) $\|u+v\|^{2} \leq\|u\|^{2}+2\langle v, u+v\rangle$;

(iii) For a sequence $\left\{u_{n}\right\}$ which converges weakly to $z \in H$, then

$$
\limsup _{n \rightarrow \infty}\left\|u_{n}-v\right\|^{2}=\limsup _{n \rightarrow \infty}\left\|u_{n}-z\right\|^{2}+\|z-v\|^{2} .
$$

Lemma 2.2 Let $H$ be a Hilbert space and $E$ be a closed, convex subset of $H$ and let $P_{E}$ be the metric projection of $H$ onto $E$. Let $u \in H$ and $z \in E$. Then $z=P_{E} u$ if and only if

$$
\langle u-z, v-z\rangle \leq 0, \quad \forall v \in E .
$$

Condition (A) A set-valued mapping $T: E \rightarrow C O(E)$ is said to satisfy Condition (A), if $\|x-p\|=d(x, T p)$, for all $x \in H$ and $p \in F(T)$.

Lemma 2.3 Let $H$ be a Hilbert space and $E$ be a closed, convex subset of $H$. Let $T: E \rightarrow C O(E)$ be a k-nonspreading set-valued mapping with $k \in\left(0, \frac{1}{2}\right]$ and $F(T) \neq \emptyset$, then $F(T)$ is closed. Also $F(T)$ is convex, if $T$ satisfies Condition (A).

Proof. Let $u_{n} \rightarrow u$ as $n \rightarrow \infty$, then it follows that

$$
\begin{aligned}
d(u, T u) & \leq\left\|u-u_{n}\right\|+d\left(u_{n}, T u\right) \leq\left\|u-u_{n}\right\|+H\left(T u_{n}, T u\right) \\
& \leq\left\|u-u_{n}\right\|+\sqrt{\frac{k}{1-k}}\left\|u_{n}-u\right\|,
\end{aligned}
$$

which implies $d(u, T u)=0$ as $n \rightarrow \infty$. Therefore $u \in F(T)$.

Now, let $x=s x_{1}+(1-s) x_{2}$, where $x_{1}, x_{2} \in F(T)$ and $s \in(0,1)$. Let $w \in T p$. It follows from (1.8) and Lemma 2.1 that

$$
\begin{aligned}
\|x-w\|^{2} & =\left\|s\left(w-x_{1}\right)+(1-s)\left(w-x_{2}\right)\right\|^{2} \\
& =s\left\|w-x_{1}\right\|^{2}+(1-s)\left\|w-x_{2}\right\|^{2}-s(1-s)\left\|x_{1}-x_{2}\right\|^{2} \\
& =s d\left(w, T x_{1}\right)^{2}+(1-s) d\left(w, T x_{2}\right)^{2}-s(1-s)\left\|x_{1}-x_{2}\right\|^{2} \\
& \leq s H\left(T x, T x_{1}\right)^{2}+(1-s) H\left(T x, T x_{2}\right)^{2}-s(1-s)\left\|x_{1}-x_{2}\right\|^{2}
\end{aligned}
$$




$$
\begin{aligned}
& \leq \theta\left[s\left\|x-x_{1}\right\|^{2}+(1-s)\left\|x-x_{2}\right\|^{2}\right]-s(1-s)\left\|x_{1}-x_{2}\right\|^{2} \\
& =s(1-s)^{2}\left\|x_{1}-x_{2}\right\|^{2}+(1-s) s^{2}\left\|x_{1}-x_{2}\right\|^{2}-s(1-s)\left\|x_{1}-x_{2}\right\|^{2} \\
& \quad=0
\end{aligned}
$$

where $\theta=\sqrt{\frac{k}{1-k}}<1$ and hence $x=w$. Therefore, $x \in F(T)$. This completes the proof.

Lemma 2.4 [15] Let Let $H$ be a Hilbert space and $E$ be a closed, convex subset of $H$. Let $T: E \rightarrow C O(E)$ be a k-nonspreading set-valued mapping such that $k \in\left(0, \frac{1}{2}\right]$. If $u, v \in E$ and $a \in T u$, then there exists $b \in T v$ such that

$$
\|a-b\|^{2} \leq H(T u, T v)^{2} \leq \frac{k}{1-k}\left(\|u-v\|^{2}+2\langle u-a, v-b\rangle\right) .
$$

Lemma 2.5 [15] Let $H$ be a Hilbert space and $E$ be a closed, convex subset of $H$. Let $T: E \rightarrow C O(E)$ be a k-nonspreading set-valued mapping such that $k \in\left(0, \frac{1}{2}\right]$. Let $\left\{x_{n}\right\}$ be a sequence in $E$ which converges weakly to $p$ and $\lim _{n \rightarrow \infty}\left\|x_{n}-y_{n}\right\|=0$ for some $y_{n} \in T x_{n}$. Then $p \in T p$.

Theorem 2.1 [2] Let $M: E \times E \rightarrow \mathbf{R}$ is a mapping with $M(u, u)=$ $0, \forall u \in E$. If $M$ is monotone, upper hemicontinuous and for each $u \in E$ fixed, the function $v \rightarrow M(u, v)$ is convex and lower semicontinuous, then for fixed $r>0$ and $z \in E$, there exists a nonempty compact convex subset $K$ of $H$ and $u \in E \cap K$ such that

$$
M(v, u)+\frac{1}{r}\langle v-u, u-z\rangle<0, \forall v \in E \backslash K .
$$

Lemma 2.6 [4] Let for each $u \in H$ and $r>0$, a mapping $T_{r}: H \rightarrow E$ is given by

$T_{r}(u)=\left\{z \in E: M(z, v)+\frac{1}{r}\langle v-z, v-u\rangle \geq 0, \forall v \in E\right\}, u \in H$

If $M: E \times E \rightarrow \mathbf{R}$ satisfies Theorem 2.1., then the following hold:

(i) $T_{r}$ is nonempty and firmly nonexpansive, i.e., for any $u, v \in H$,

$$
\left\|T_{r} u-T_{r} v\right\|^{2} \leq\left\langle T_{r} u-T_{r} v, u-v\right\rangle ;
$$


(ii) $F\left(T_{r}\right)=E P(M)$ and $E P(M)$ is convex and closed.

Lemma 2.7 [17] Let $H$ be a Hilbert space and $E$ be a closed, convex subset of $H$. For each $i \in N$, let a mapping $M_{i}: E \times E \rightarrow \mathbf{R}$ follows Theorem 2.1 with $\bigcap_{i=1}^{N} E P\left(M_{i}\right) \neq \emptyset$.

Then

$$
E P\left(\sum_{i=1}^{N} a_{i} M_{i}\right)=\bigcap_{i=1}^{N} E P\left(M_{i}\right)
$$

where $a_{i} \in(0,1)$ for $i=1,2, \ldots, N$ and $\sum_{i=1}^{N} a_{i}=1$.

\section{Example 2.1 Let}

$$
\begin{aligned}
& M_{1}(u, v)=\frac{1}{2}(u-1)\left(5 v^{2}-u^{2}-4 u v\right), \\
& M_{2}(u, v)=(u-1)\left(v^{2}-u^{2}\right), \\
& M_{3}(u, v)=(u-1)\left(u v+v^{2}-2 u^{2}\right), \quad \forall u, v \in \mathbf{R},
\end{aligned}
$$

where $M_{i}: \mathbf{R} \times \mathbf{R} \rightarrow \mathbf{R}$ for $i=1,2,3$. It can be seen that $M_{i}(u, v)$ satisfies Theorem 2.1 for each $i$ and $\bigcap_{i=1}^{3} E P\left(M_{i}\right)=\{0,1\}$.

If we take $a_{1}=\frac{1}{4}, a_{2}=\frac{1}{12}$ and $a_{3}=\frac{2}{3}$, then

$$
\sum_{i=1}^{3} a_{i} M_{i}(u, v)=\frac{1}{24}(u-1)\left(4 u v+33 v^{2}-37 u^{2}\right),
$$

which yields $E P\left(\sum_{i=1}^{N} a_{i} M_{i}\right)=\{0,1\}$.

Remark 2.1 [17] From Lemma 2.6, we obtain

$$
F\left(T_{r}^{\sum}\right)=E P\left(\sum_{i=1}^{N} a_{i} M_{i}\right)=\bigcap_{i=1}^{N} E P\left(M_{i}\right),
$$

where

$T_{r}^{\sum}(u)=\left\{z \in E:\left(\sum_{i=1}^{N} a_{i} M_{i}\right)(z, v)+\frac{1}{r}\langle v-z, z-u\rangle \geq 0, \forall v \in E\right\}$,

and $a_{i} \in(0,1)$, for each $i$ and $\sum_{i=1}^{N} a_{i}=1$. 


\section{Main Result}

Now we give our main Theorem of finding strong convergence result for common solutions of $G E P(1.3)$ and the fixed points of a $k$-nonspreading set-valued mapping.

Theorem 3.1 Let $H$ be a Hilbert space and $E$ be a closed, convex subset of $H$. For each $i \in N$, suppose $M_{i}: E \times E \rightarrow \mathbf{R}$ be a bi mapping satisfying Theorem 2.1. Let $T: E \rightarrow C O(E)$ be a k-nonspreading set-valued mapping with $k \in\left(0, \frac{1}{2}\right]$. Assume $\Omega=\bigcap_{i=1}^{N} E P\left(M_{i}\right) \cap F(T) \neq \emptyset$. For given initial point $x_{1} \in H$ with $K_{1}=E$, let $\left\{u_{n}\right\},\left\{y_{n}\right\}$ and $\left\{x_{n}\right\}$ are given by

$$
\left\{\begin{array}{l}
u_{n} \in E \text { such that } \sum_{i=1}^{N} a_{i} M_{i}\left(u_{n}, y\right)+\frac{1}{r_{n}}\left\langle y-u_{n}, u_{n}-x_{n}\right\rangle \geq 0, \quad \forall y \in E \\
y_{n} \in \alpha_{n} u_{n}+\left(1-\alpha_{n}\right) T u_{n} \\
E_{n}=\left\{z \in E:\left\|y_{n}-z\right\| \leq\left\|x_{n}-z\right\|\right\} \\
K_{n}=\left\{z \in K_{n-1}:\left\langle x_{1}-x_{n}, z-x_{n}\right\rangle \leq 0\right\}, n \geq 2 \\
x_{n+1}=P_{E_{n} \cap K_{n}} x_{1}, n \geq 1
\end{array}\right.
$$

If $T$ satisfies Condition (A) and $\left\{r_{n}\right\} \subset(0, \infty)$ satisfies $\liminf _{n \rightarrow \infty} r_{n}>0$ with $\left\{\alpha_{n}\right\} \subset(0,1)$, then $\left\{x_{n}\right\}$ converges strongly to $P_{\Omega} x_{1}$.

Proof. The proof can be divided into the following steps.

Step 1. We claim that $\left\{x_{n}\right\}$ is well defined.

It can easily seen from the definition that $E_{n}$ is closed and $K_{n}$ is closed and convex for every $n \in \mathbf{N}$. We claim that $E_{n}$ is convex. Since $E_{n}=\{z \in$ $\left.E:\left\|y_{n}-z\right\| \leq\left\|x_{n}-z\right\|\right\}$ which can be given as

$$
E_{n}=\left\{z \in E:\left\|y_{n}-x_{n}\right\|^{2}+2\left\langle y_{n}-x_{n}, x_{n}-z\right\rangle \leq 0\right\},
$$

which implies that $E_{n}$ is convex. Therefore, $E_{n} \cap K_{n}$ is closed and convex subset of $H$ for each $n \in \mathbf{N}$. Hence $P_{E_{n} \cap K_{n}} x_{1}$ is well defined and as a result $\left\{x_{n}\right\}$ is well defined.

From Lemma 2.6 and Remark 2.1 it can be concluded that $E P\left(\sum_{i=1}^{N} a_{i} M_{i}\right)$ is closed and convex. Further from Lemma 2.3, it can be concluded that $F(T)$ is closed and convex. Consequently, $\Omega$ is closed and convex and therefore $P_{\Omega} x_{1}$ is well defined. 
Step 2. We claim that $\Omega \subset E_{n} \cap K_{n}$.

Let $p \in \bigcap_{i=1}^{N} E P\left(M_{i}\right) \cap F(T)$, then by using Lemma 2.6 , we have $u_{n}=T_{r_{n}}^{\sum_{n}}$ and

$$
\left\|u_{n}-p\right\|=\left\|T_{r_{n}}^{\sum_{n}} x_{n}-T_{r_{n}}^{\sum_{p}} p\right\| \leq\left\|x_{n}-p\right\|
$$

for all $n \in \mathbf{N}$. Now we have

$$
\begin{aligned}
\left\|y_{n}-p\right\| & =\left\|\alpha_{n} u_{n}+\left(1-\alpha_{n}\right) z_{n}-p\right\| \\
& \leq \alpha_{n}\left\|u_{n}-p\right\|+\left(1-\alpha_{n}\right)\left\|z_{n}-p\right\| \\
& =\alpha_{n}\left\|u_{n}-p\right\|+\left(1-\alpha_{n}\right) d\left(z_{n}, T p\right) \\
& \leq \alpha_{n}\left\|u_{n}-p\right\|+\left(1-\alpha_{n}\right) H\left(T u_{n}, T p\right) \\
& \leq \alpha_{n}\left\|u_{n}-p\right\|+\left(1-\alpha_{n}\right) \theta\left\|u_{n}-p\right\| \\
& \leq\left\|u_{n}-p\right\|,
\end{aligned}
$$

for all $z_{n} \in T u_{n}$, where $\theta=\sqrt{\frac{k}{1-k}}<1$. So, we have $p \in E_{n}$ and hence

$$
\bigcap_{i=1}^{N} E P\left(M_{i}\right) \cap F(T) \subset E_{n}, \text { for all } n \in \mathbf{N} \text {. }
$$

Further, we claim that

$$
\bigcap_{i=1}^{N} E P\left(M_{i}\right) \cap F(T) \subset E_{n} \cap K_{n} \text {, for all } n \in \mathbf{N} \text {. }
$$

It can be proved by using induction. For $n=1$, we have $\bigcap_{i=1}^{N} E P\left(M_{i}\right) \cap$ $F(T) \subset E_{1}$ and $K_{1}=H$, we get $\bigcap_{i=1}^{N} E P\left(M_{i}\right) \cap F(T) \subset E_{1} \cap K_{1}$. Let $\bigcap_{i=1}^{N} E P\left(M_{i}\right) \cap F(T) \subset E_{n} \cap K_{n}$ for some $n$. Since $x_{n+1}=P_{E_{n} \cap K_{n}} x_{1}$, then $x_{n+1} \in E_{n} \cap K_{n}$ and

$\left\langle x_{1}-x_{n+1}, z-x_{n+1}\right\rangle \leq 0$, for all $z \in E_{n} \cap K_{n}$.

Since $\bigcap_{i=1}^{N} E P\left(M_{i}\right) \cap F(T) \subset E_{n} \cap K_{n}$, for all $z \in \bigcap_{i=1}^{N} E P\left(M_{i}\right) \cap F(T)$

$$
\left\langle x_{1}-x_{n+1}, z-x_{n+1}\right\rangle \leq 0,
$$


and hence $z \in K_{n+1}$. So, we get

$$
\bigcap_{i=1}^{N} E P\left(M_{i}\right) \cap F(T) \subset K_{n+1} \text { for all } n \in \mathbf{N} \text {. }
$$

By using (3.4) we have

$$
\bigcap_{i=1}^{N} E P\left(M_{i}\right) \cap F(T) \subset E_{n+1} \cap K_{n+1}, \quad \text { for all } n \in \mathbf{N} .
$$

Hence $\Omega \subset E_{n} \cap K_{n}$, for all $n \in \mathbf{N}$.

Step 3. We claim that $\lim _{n \rightarrow \infty}\left\|x_{n}-x_{1}\right\|$ exists.

Since nonempty set $\Omega$ is closed and convex therefore there exists a unique $v \in \Omega$ in $H$ such that $v=P_{\Omega} x_{1}$. From $x_{n+1}=P_{E_{n} \cap K_{n}} x_{1}$, it follows that

$\left\|x_{n+1}-x_{1}\right\| \leq\left\|z-x_{1}\right\|$, for all $z \in E_{n} \cap K_{n}$ and all $n \in \mathbf{N}$.

Since $v \in \Omega \subset E_{n} \cap K_{n}$, we have

$\left\|x_{n+1}-x_{1}\right\| \leq\left\|v-x_{1}\right\|$, for all $n \in \mathbf{N}$.

Therefore, $\left\{x_{n}\right\}$ is bounded. Again (3.2) and (3.3) $\left\{u_{n}\right\}$ and $\left\{y_{n}\right\}$ are bounded.

Since $x_{n}=P_{K_{n}} x_{1}$ and $x_{n+1} \in K_{n}$, for all $n$, we have

$\left\|x_{n}-x_{1}\right\| \leq\left\|x_{n+1}-x_{1}\right\|$, for all $n \in \mathbf{N}$.

As $\left\{x_{n}\right\}$ is bounded, therefore $\left\{\left\|x_{n}-x_{1}\right\|\right\}$ is nondecreasing and bounded. Therefore $\lim _{n \rightarrow \infty}\left\|x_{n}-x_{1}\right\|$ exists.

Step 4. We claim that $\lim _{n \rightarrow \infty} x_{n}=w \in E$.

Since $m>n$, therefore from $K_{n}$ we have $K_{m} \subset K_{n}$. Since $x_{m}=P_{K_{m}} x_{1} \subset$ $K_{n}$ and $x_{n}=P_{K_{n}} x_{1}$, it follows from (2.1) that

$$
\left\|x_{m}-x_{n}\right\|^{2} \leq\left\|x_{m}-x_{1}\right\|^{2}-\left\|x_{n}-x_{1}\right\|^{2} .
$$

Since $\lim _{n \rightarrow \infty}\left\|x_{n}-x_{1}\right\|$ exists, above inequality gives

$$
\lim _{n \rightarrow \infty}\left\|x_{m}-x_{n}\right\|=0
$$


therefore $\left\{x_{n}\right\}$ is a Cauchy sequence in $E$ and there exists $w \in E$ such that $\lim _{n \rightarrow \infty} x_{n}=w$. Particularly if $m=n+1$, then (3.7) gives

$$
\lim _{n \rightarrow \infty}\left\|x_{n}-x_{n+1}\right\|=0
$$

Step 5. We claim that $w \in F(T)$.

As $x_{n+1} \in E_{n}$, therefore

$$
\left\|x_{n}-y_{n}\right\| \leq\left\|x_{n}-x_{n+1}\right\|+\left\|x_{n+1}-y_{n}\right\| \leq 2\left\|x_{n}-x_{n+1}\right\| .
$$

Since $\lim _{n \rightarrow \infty}\left\|x_{n}-x_{n+1}\right\|=0$, therefore we get

$$
\lim _{n \rightarrow \infty}\left\|x_{n}-y_{n}\right\|=0 .
$$

Since $p \in \bigcap_{i=1}^{N} E P\left(M_{i}\right) \cap F(T)$ and $T_{r}^{\sum}$ is firmly nonexpansive, we have

$$
\begin{aligned}
\left\|u_{n}-p\right\|^{2}=\left\|T_{r_{n}}^{\sum_{n}} x_{n}-T_{r_{n}}^{\sum_{p}} p\right\|^{2} & \leq\left\langle T_{r_{n}}^{\sum_{n}} x_{n}-T_{r_{n}}^{\sum_{n}} p, x_{n}-p\right\rangle \\
& =\left\langle u_{n}-p, x_{n}-p\right\rangle \\
& =\frac{1}{2}\left\{\left\|u_{n}-p\right\|^{2}+\left\|x_{n}-p\right\|^{2}-\left\|x_{n}-u_{n}\right\|^{2}\right\} .
\end{aligned}
$$

Hence,

$$
\left\|u_{n}-p\right\|^{2} \leq\left\|x_{n}-p\right\|^{2}-\left\|x_{n}-u_{n}\right\|^{2} .
$$

For $z_{n} \in T u_{n}$, it follows from (3.2) that

$$
\begin{aligned}
\left\|y_{n}-p\right\|^{2} & \leq \alpha_{n}\left\|u_{n}-p\right\|^{2}+\left(1-\alpha_{n}\right)\left\|z_{n}-p\right\|^{2} \\
& \leq \alpha_{n}\left\|x_{n}-p\right\|^{2}+\left(1-\alpha_{n}\right) d\left(z_{n}, T p\right)^{2} \\
& \leq \alpha_{n}\left\|x_{n}-p\right\|^{2}+\left(1-\alpha_{n}\right) H\left(T u_{n}, T p\right)^{2} \\
& \leq \alpha_{n}\left\|x_{n}-p\right\|^{2}+\left(1-\alpha_{n}\right) \theta^{2}\left\|u_{n}-p\right\|^{2} .
\end{aligned}
$$

Since $\alpha<1$, it follows from (3.10) that

$\left\|y_{n}-p\right\|^{2} \leq\left\|x_{n}-p\right\|^{2}-\left(1-\alpha_{n}\right) \theta^{2}\left\|x_{n}-u_{n}\right\|^{2}$ 
which can be written as

$$
\begin{aligned}
\left(1-\alpha_{n}\right) \theta^{2}\left\|x_{n}-u_{n}\right\|^{2} & \leq\left\|x_{n}-p\right\|^{2}-\left\|y_{n}-p\right\|^{2} . \\
& \leq\left\|x_{n}-y_{n}\right\|\left(\left\|x_{n}-p\right\|+\left\|y_{n}-p\right\|\right) .
\end{aligned}
$$

Since $\left(1-\alpha_{n}\right) \theta^{2}>0$, it follows from (3.9) and (3.11) that

$$
\lim _{n \rightarrow \infty}\left\|x_{n}-u_{n}\right\|=0 .
$$

Since $y_{n} \in \alpha_{n} u_{n}+\left(1-\alpha_{n}\right) T u_{n}$, then for any $z_{n} \in T u_{n}$ we have

$$
\left(1-\alpha_{n}\right)\left\|z_{n}-u_{n}\right\|=\left\|y_{n}-u_{n}\right\| \leq\left\|y_{n}-x_{n}\right\|+\left\|x_{n}-u_{n}\right\| .
$$

Since $\left(1-\alpha_{n}\right)>0$, it follows from (3.9), (3.12) and (3.13) that

$$
\lim _{n \rightarrow \infty}\left\|z_{n}-u_{n}\right\|=0 \text {. }
$$

It follows from (3.12) and (3.14) that the sequences $\left\{x_{n}\right\},\left\{u_{n}\right\}$ and $\left\{z_{n}\right\}$ all have the same asymptotic behaviour and hence $u_{n} \rightarrow w$ and $z_{n} \rightarrow w$ as $n \rightarrow \infty$. Hence, by Lemma 2.5, we have $w \in F(T)$.

Step 6. We claim that $w \in \bigcap_{i=1}^{N} E P\left(M_{i}\right)$.

Since $u_{n}=T_{r_{n}} x_{n}$, we have

$$
\sum_{i=1}^{N} a_{i} M_{i}\left(u_{n}, y\right)+\frac{1}{r_{n}}\left\langle y-u_{n}, u_{n}-x_{n}\right\rangle \geq 0, \quad \forall y \in E .
$$

From monotonicity of Theorem 2.1, above can be written as

$$
\frac{1}{r_{n}}\left\langle y-u_{n}, u_{n}-x_{n}\right\rangle \geq \sum_{i=1}^{N} a_{i} M_{i}\left(y, u_{n}\right), \quad \forall y \in E .
$$

Since $\liminf _{n \rightarrow \infty} r_{n}>0$, there exists $r>0$ such that $r_{n}>r, \forall n$. Hence, it follows that

$$
\lim _{n \rightarrow \infty} \frac{\left\|u_{n}-x_{n}\right\|}{r_{n}}<\lim _{n \rightarrow \infty} \frac{\left\|u_{n}-x_{n}\right\|}{r}=0 .
$$

It follows from (3.12), (3.15), (3.16) and Theorem 2.1 that

$$
\sum_{i=1}^{N} a_{i} M_{i}(y, w) \leq 0, \quad \forall y \in E .
$$


For $s \in(0,1]$ and $y \in E$, assume $y_{s}:=s y+(1-s) w$. For each $y \in E$, we have $y_{s} \in E$ and therefore $\sum_{i=1}^{N} a_{i} M_{i}\left(y_{s}, w\right) \leq 0$. Now we have

$$
\begin{aligned}
0 & =\sum_{i=1}^{N} a_{i} M_{i}\left(y_{s}, y_{s}\right) \\
& =\sum_{i=1}^{N} a_{i} M_{i}\left(y_{s}, s y+(1-s) w\right) \\
\leq & \left.s \sum_{i=1}^{N} a_{i} M_{i}\left(y_{s}, y\right)+(1-s) \sum_{i=1}^{N} a_{i} M_{i}\left(y_{s}, w\right)\right) \\
& \leq s \sum_{i=1}^{N} a_{i} M_{i}\left(y_{s}, y\right) .
\end{aligned}
$$

After dividing by $s$, it follows that

$\sum_{i=1}^{N} a_{i} M_{i}(t y+(1-t) w, y) \geq 0 \forall y \in E$.

From Theorem 2.1 and taking $t \downarrow 0$, we have

$\sum_{i=1}^{N} a_{i} M_{i}(w, y) \geq 0 \forall y \in E$

Which implies, $w \in E P\left(\sum_{i=1}^{N} a_{i} M_{i}\right)$. By using Lemma 2.7,

$$
E P\left(\sum_{i=1}^{N} a_{i} M_{i}\right)=\bigcap_{i=1}^{N} E P\left(M_{i}\right)
$$

Therefore, we obtain $w \in \bigcap_{i=1}^{N} E P\left(M_{i}\right) \cap F(T)$.

Step 7. We claim that $w=P_{\Omega} x_{1}$.

Since $x_{n}=P_{K_{n}} x_{1}$ and $w \in \bigcap_{i=1}^{N} E P\left(M_{i}\right) \cap F(T) \subset K_{n}$, we have

$$
\left\langle x_{1}-x_{n}, x_{n}-p\right\rangle \geq 0, \quad \forall p \in K_{n} .
$$


Applying $n \rightarrow \infty$ in (3.17), we have

$$
\left\langle x_{1}-w, w-p\right\rangle \geq 0, \quad \forall p \in K_{n} .
$$

Since $\Omega \subset K_{n}$, we have

$$
\left\langle x_{1}-w, w-p\right\rangle \geq 0, \quad \forall p \in \Omega,
$$

which gives $w=P_{\Omega} x_{1}$.

Based on Theorem 3.1, we have following consequences.

Corollary 3.1 Let $H$ be a Hilbert space and $E$ be a closed, convex subset of $H$. Let $M: E \times E \rightarrow \mathbf{R}$ satisfying Theorem 2.1 such that $E P(M) \neq \emptyset$. For a given initial point $x_{1} \in H$ with $K_{1}=E$, let $\left\{u_{n}\right\}$ and $\left\{x_{n}\right\}$ is given by

$$
\left\{\begin{array}{l}
u_{n} \in E \text { such that } M\left(u_{n}, y\right)+\frac{1}{r_{n}}\left\langle y-u_{n}, u_{n}-x_{n}\right\rangle \geq 0, \quad \forall y \in E, \\
E_{n}=\left\{z \in E:\left\|y_{n}-z\right\| \leq\left\|x_{n}-z\right\|\right\} \\
K_{n}=\left\{z \in K_{n-1}:\left\langle x_{1}-x_{n}, z-x_{n}\right\rangle \leq 0\right\}, n \geq 2 \\
x_{n+1}=P_{E_{n} \cap K_{n}} x_{1}, n \geq 1
\end{array}\right.
$$

where $\left\{r_{n}\right\} \subset(0, \infty)$ satisfies $\liminf _{n \rightarrow \infty} r_{n}>0$. Then $\left\{x_{n}\right\}$ converges strongly to $P_{E P(M)} x_{1}$.

Proof. By taking $M_{i}=M$, for each $i$ and $T=I$ with $\alpha_{n}=1$, the Theorem 3.1, reduces to Corollary 3.1.

Corollary 3.2 Let $H$ be a Hilbert space and $E$ be a closed, convex subset of $H$. Let $T: E \rightarrow C O(E)$ be a k-nonspreading set-valued mapping with $k \in\left(0, \frac{1}{2}\right]$ such that $F(T) \neq \emptyset$. For a given initial point $x_{1} \in H$ with $K_{1}=E$, let the sequences $\left\{u_{n}\right\},\left\{y_{n}\right\}$ and $\left\{x_{n}\right\}$ are given by

$$
\left\{\begin{array}{l}
u_{n} \in E \text { such that }\left\langle y-u_{n}, u_{n}-x_{n}\right\rangle \geq 0, \quad \forall y \in E \\
y_{n} \in \alpha_{n} u_{n}+\left(1-\alpha_{n}\right) T u_{n} \\
E_{n}=\left\{z \in E:\left\|y_{n}-z\right\| \leq\left\|x_{n}-z\right\|\right\} \\
K_{n}=\left\{z \in K_{n-1}:\left\langle x_{1}-x_{n}, z-x_{n}\right\rangle \leq 0\right\}, n \geq 2 \\
x_{n+1}=P_{E_{n} \cap K_{n}} x_{1}, n \geq 1
\end{array}\right.
$$

where $\left\{\alpha_{n}\right\} \subset(0,1)$. If $T$ satisfies condition $(A)$, then $\left\{x_{n}\right\}$ converges strongly to $P_{F(T)} x_{1}$.

Proof. By taking $M_{i}=0$, for each $i$ with $r_{n}=1$ the Theorem 3.1 reduces to Corollary 3.2. 


\section{Numerical Illustrations}

Now, an example to understand and verify the convergence nature of main result 3.1 is given as follows:

Example 4.1 Let $M_{i}:[1,4] \times[1,4] \rightarrow \mathbf{R}$ be defined by

$$
M_{i}(x, y)=i\left(y^{2}-2 x^{2}+x y+3 x-3 y\right), \text { for all } x, y \in[1,4],
$$

for each $i \in N$ and $\mathbf{R}=H, E=[1,4]$. Further, let $a_{i}=\frac{4}{5^{i}}+\frac{1}{N 5^{N}}$ such that $\sum_{i=1}^{N} a_{i}=1$, where $i \in N$. Now

$\sum_{i=1}^{N} a_{i} M_{i}(x, y)=\sum_{i=1}^{N}\left(\frac{4}{5^{i}}+\frac{1}{N 5^{N}}\right) i\left(y^{2}-2 x^{2}+x y+3 x-3 y\right)=\Psi\left(y^{2}-2 x^{2}+x y+3 x-3 y\right)$,

where $\Psi=\sum_{i=1}^{N}\left(\frac{4}{5^{i}}+\frac{1}{N 5^{N}}\right) i$. It can be easily seen that $\sum_{i=1}^{N} a_{i} M_{i}$ satisfies Theorem 3.1 and

$$
E P\left(\sum_{i=1}^{N} a_{i} M_{i}\right)=\bigcap_{i=1}^{N} E P\left(M_{i}\right)=\{1\} .
$$

Let be a mapping $T: E \rightarrow C O(E)$ by

$$
T x= \begin{cases}\{1\}, & x \in[1,3] \\ {\left[\frac{x}{x+1}, 1\right],} & x \in(3,4] .\end{cases}
$$

Now, we show that $T$ is $\frac{1}{2}$-nonspreading set-valued mapping. In fact, we have the following cases:

Case 1: if $x, y \in[1,3]$, then $H(T x, T y)=0$.

Case 2: if $x \in[1,3]$ and $y \in(3,4]$, then

$2 H(T x, T y)^{2}=2\left(1-\frac{y}{y+1}\right)^{2}<2<d(T x, y)^{2}+d(x, T y)^{2}$.

Case 3: if $x, y \in(3,4]$, then

$2 H(T x, T y)^{2}=2\left(\frac{x}{x+1}-\frac{y}{y+1}\right)^{2}<2<d(T x, y)^{2}+d(x, T y)^{2}$, 
which shows that $T$ is $\frac{1}{2}$-nonspreading set-valued mapping.

It is easy to see that $\bigcap_{i=1}^{N} E P\left(M_{i}\right) \cap F(T)=\{1\}$.

Step 1. Find $\left\{u_{n}\right\}$ in $E=[1,4]$.

For $r_{n}>0$, we have $\left\{x_{n}\right\}$ and $\left\{u_{n}\right\}$ in $E$ such that

$\sum_{i=1}^{N} a_{i} M_{i}\left(u_{n}, y\right)+\frac{1}{r_{n}}\left\langle y-u_{n}, u_{n}-x_{n}\right\rangle \geq 0, \forall y \in E$,

it can be written as

$S(y):=\Psi r_{n} y^{2}+\left(\Psi u_{n} r_{n}+u_{n}-x_{n}-3 \Psi r_{n}\right) y+3 \Psi r_{n} u_{n}-u_{n}^{2}-2 \Psi r_{n} u_{n}^{2}+u_{n} x_{n} \geq 0, \quad \forall y \in E$.

As $S(y)=a y^{2}+b y+c \geq 0$, for all $y \in E$ then $b^{2}-4 a c=\left(u_{n}-3 \Psi r_{n}+\right.$ $\left.3 \Psi r_{n} u_{n}-x_{n}\right)^{2} \leq 0$. Therefore, $\left(u_{n}-3 \Psi r_{n}+3 \Psi r_{n} u_{n}-x_{n}\right)^{2}=0$ which implies that

$$
u_{n}=\frac{x_{n}+3 \Psi r_{n}}{1+3 \Psi r_{n}}
$$

Therefore, $u_{n}=T_{r_{n}}^{\sum_{n}} x_{n}=\frac{x_{n}+3 \Psi r_{n}}{1+3 \Psi r_{n}}$ for each $r_{n}>0$.

Step 2. Find $y_{n} \in \alpha_{n} u_{n}+\left(1-\alpha_{n}\right) T u_{n}$.

By choosing $\alpha_{n}=r_{n}=\frac{n}{100 n+1}$, we have $y_{n} \in \frac{n}{100 n+1} u_{n}+\left(1-\frac{n}{100 n+1}\right) z_{n}$, where

$$
z_{n} \in \begin{cases}\{1\}, & u_{n} \in[1,3] \\ {\left[\frac{u_{n}}{u_{n+1}}, 1\right],} & u_{n} \in(3,4] .\end{cases}
$$




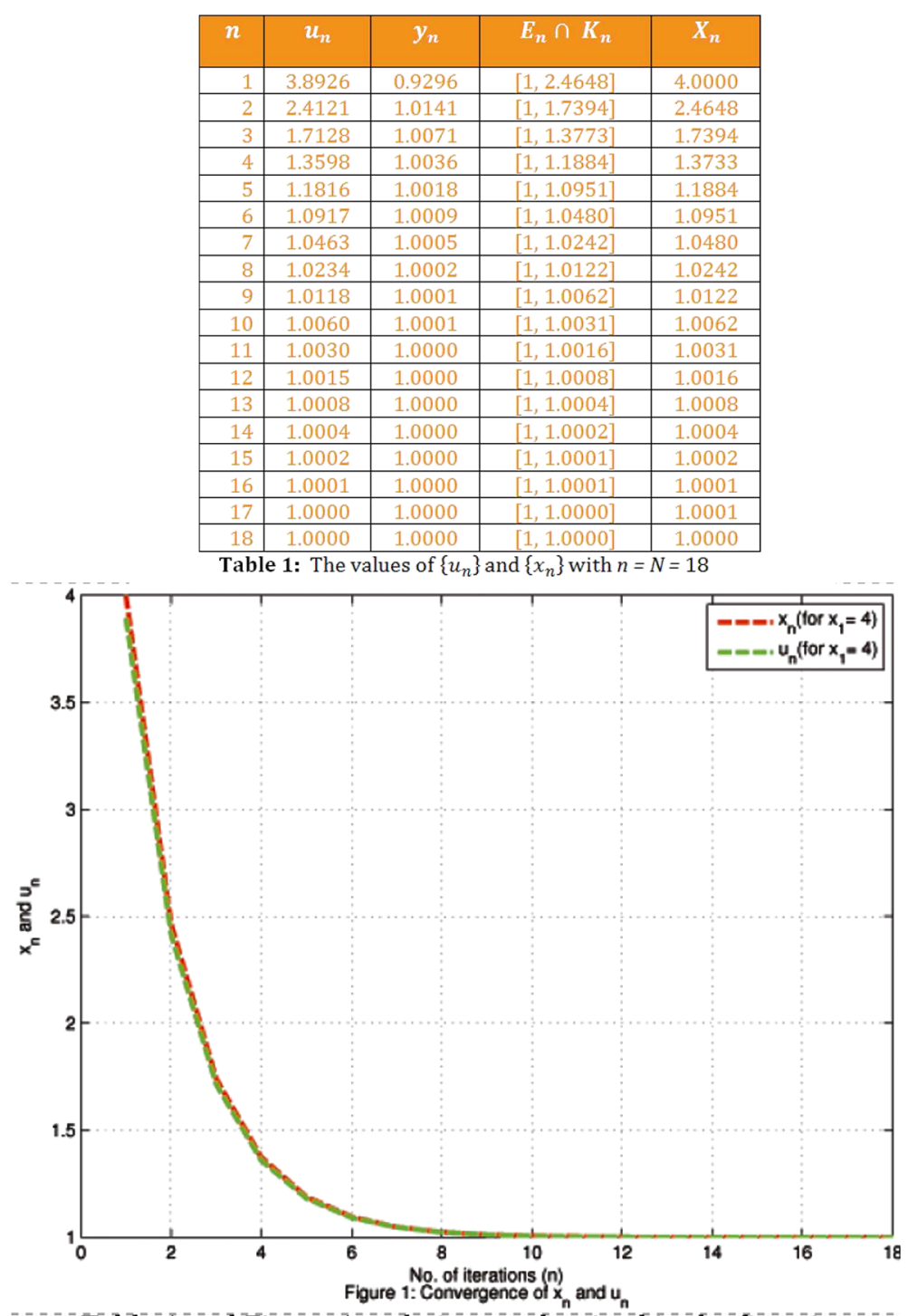

Table 1 and Figure 1: $\mathrm{z}_{\mathrm{n}}$ : being randomized in the first time

Step 3. Find $E_{n}=\left\{z \in E:\left\|y_{n}-z\right\| \leq\left\|x_{n}-z\right\|\right\}$.

Since $\left(2 z-\left(x_{n}+y_{n}\right)\right)\left(x_{n}-y_{n}\right) \leq 0$, therefore we have:

Case 1: If $x_{n}-y_{n}=0$, then $E_{n}=E, \forall n \geq 1$.

Case 2: If $x_{n}-y_{n}>0$, then $E_{n}=\left[1, \frac{x_{n}+y_{n}}{2}\right], \forall n \geq 1$.

Case 3: If $x_{n}-y_{n}<0$, then $E_{n}=\left[\frac{x_{n}+y_{n}^{2}}{2}, 4\right], \forall n \geq 1$. 
Step 4. Find $K_{n}=\left\{z \in K_{n-1}:\left\langle x_{1}-x_{n}, z-x_{n}\right\rangle \leq 0\right\}$.

Since $\left(x_{1}-x_{n}\right)\left(z-x_{n}\right) \leq 0$, therefore we have:

Case 1: If $x_{1}-x_{n}=0$, then $K_{n}=E, \forall n \geq 2$.

Case 2: If $x_{1}-x_{n}>0$, then $K_{n}=K_{n-1} \cap\left[1, x_{n}\right], \forall n \geq 2$.

Case 2: If $x_{1}-x_{n}<0$, then $K_{n}=K_{n-1} \cap\left[x_{n}, 4\right], \forall n \geq 2$.

\begin{tabular}{|r|c|c|c|c|}
\hline \multicolumn{1}{|r|}{$n$} & $u_{n}$ & $y_{n}$ & $\boldsymbol{E}_{n} \cap \boldsymbol{K}_{n}$ & $\boldsymbol{X}_{n}$ \\
\hline 1 & 3.8926 & 0.8603 & {$[1,2.4302]$} & 4.0000 \\
\hline 2 & 2.3787 & 1.0137 & {$[1,1.7219]$} & 2.4302 \\
\hline 3 & 1.6959 & 1.0069 & {$[1,1.3644]$} & 1.7219 \\
\hline 4 & 1.3513 & 1.0035 & {$[1,1.1840]$} & 1.3644 \\
\hline 5 & 1.1773 & 1.0018 & {$[1,1.0929]$} & 1.1840 \\
\hline 6 & 1.0895 & 1.0009 & {$[1,1.0469]$} & 1.0929 \\
\hline 7 & 1.0452 & 1.0005 & {$[1,1.0237]$} & 1.0469 \\
\hline 8 & 1.0228 & 1.0002 & {$[1,1.0119]$} & 1.0237 \\
\hline 9 & 1.0115 & 1.0001 & {$[1,1.0060]$} & 1.0119 \\
\hline 10 & 1.0058 & 1.0001 & {$[1,1.0030]$} & 1.0060 \\
\hline 11 & 1.0029 & 1.0000 & {$[1,1.0015]$} & 1.0030 \\
\hline 12 & 1.0015 & 1.0000 & {$[1,1.0008]$} & 1.0015 \\
\hline 13 & 1.0007 & 1.0000 & {$[1,1.0004]$} & 1.0008 \\
\hline 14 & 1.0004 & 1.0000 & {$[1,1.0002]$} & 1.0004 \\
\hline 15 & 1.0002 & 1.0000 & {$[1,1.0001]$} & 1.0002 \\
\hline 16 & 1.0001 & 1.0000 & {$[1,1.0001]$} & 1.0001 \\
\hline 17 & 1.0000 & 1.0000 & {$[1,1.0000]$} & 1.0001 \\
\hline 18 & 1.0000 & 1.0000 & {$[1,1.0000]$} & 1.0000 \\
\hline \multicolumn{5}{|r|}{ Table 2: The values of $\left\{u_{n}\right\}$ and $\left\{x_{n}\right\}$ with $n=N=18$} \\
\hline
\end{tabular}

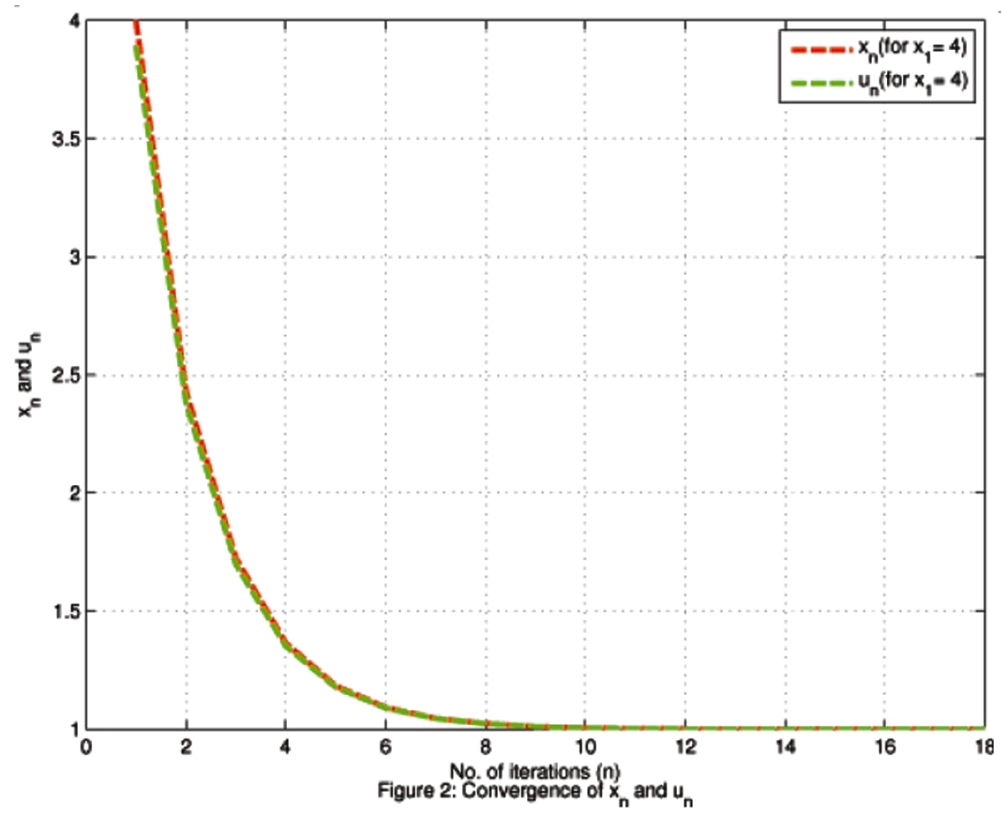

Table 2 and Figure 2: Chosen $z_{n}$ randomly 
Step 5. Solve $x_{n+1}=P_{E_{n} \cap K_{n}} x_{1}$.

By taking $n=N=18$ and choosing $x_{1}=4$, the scheme (3.1) converges to 1 (see the table 1 , table 2 and figure 1 , figure 2 ).

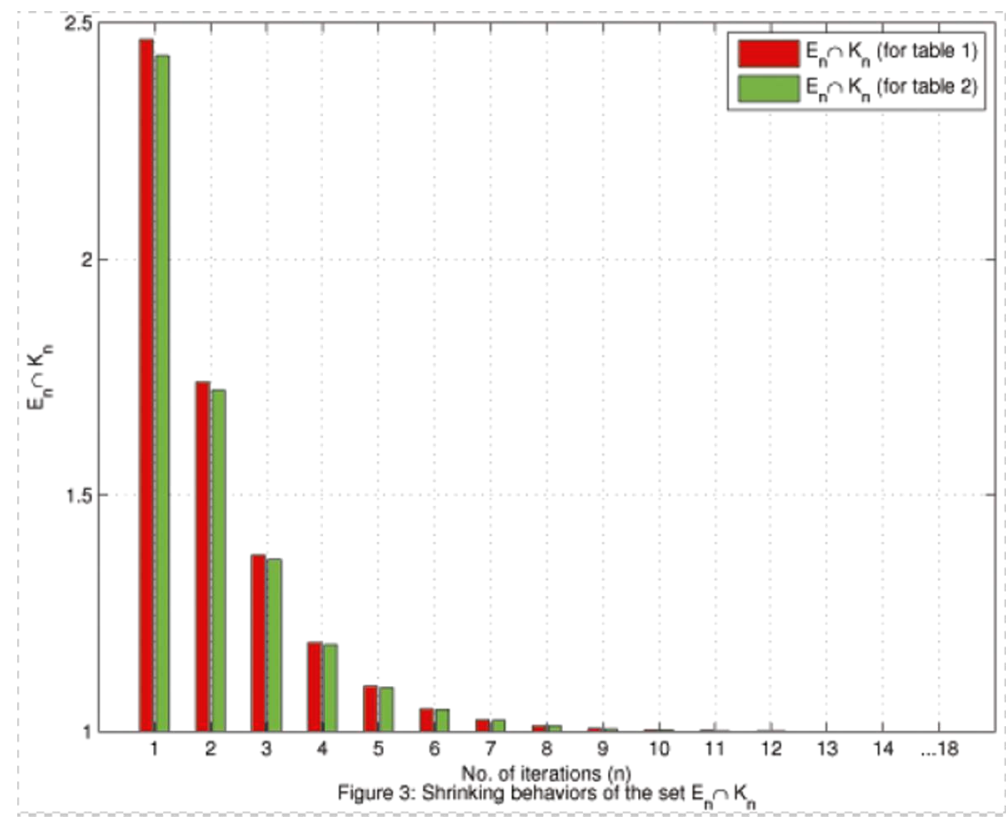

Figure 3: Shrinking behavior of $E_{n} \cap K_{n}$

Figure 3, shows the trend of $E_{n} \cap K_{n}$, that is $E_{n} \cap K_{n} \subset E_{n-1} \cap K_{n-1} \ldots \subset$ $E_{2} \cap K_{2} \subset E_{1} \cap K_{1} \subset E$. It can be concluded that the iteration of $E_{n} \cap K_{n}$ will be shrinked till we obtain the approximate result.

\section{Conclusion}

In this work, we studied a new method which is known as shrinking projection hybrid iteration technique for finding simultaneous solution of a generalized equilibrium problems $G E P$ (1.3) and a fixed point problem for a $k$-nonspreading set-valued mapping with $k \in\left(0, \frac{1}{2}\right]$ in Hilbert space. Next, we establish a main result for the converging sequences given by the shrinking projection hybrid method and given some of consequences. Finally, we show by an example that our method is better than existing methods. By making use of iteration method presented in this work, we can find the main result for the problems considered in [17]. 


\section{References}

[1] A. Bnouhachem, "A hybrid iterative method for a combination of equilibria problem, a combination of variational inequality problems and a hierarchical fixed point problem", Fixed point theory and applications, vol. 2014, no. 1, Art ID. 163, Jul. 2014, doi: 10.1186/1687-1812-2014163

[2] E. Blum and W. Oettli, "From optimization and variational inequalities to equilibrium problems", The mathematics student, vol. 63, no. 1-4, pp. 123-145, 1994.

[3] W. Cholamjiak and S. Suantai, "A new hybrid algorithm for a countable family of quasi-nonexpansive mappings and equilibrium problems", Journal of nonlinear and convex analysis, vol. 12, no. 2, pp. 381-398, Aug. 2011. [On line]. Available: https://bit.ly/2ZEIDfL

[4] P. L. Combettes and S. A. Hirstoaga, "Equilibrium programming in Hilbert spaces", Journal of nonlinear and convex analysis, vol. 6, pp. 117-136, 2005. [On line]- Available: https://bit.ly/3grPBti

[5] S. Iemoto and W. Takahashi, "Approximating common fixed points of nonexpansive mappings and nonspreading mappings in a Hilbert space", Nonlinear analysis: theory, methods \& applications, vol. 71, no. 12, pp. e2082-e2089, Dec. 2009, doi: 10.1016/j.na.2009.03.064

[6] K. R. Kazmi, R. Ali, and S. H. Rizvi, "Common solution of a combination of split general variational-like inequality problems and a family of generalized asymptotically nonexpansive mappings", Journal of advanced mathematical studies, vol. 10, no. 2, pp. 200-215, 2017.

[7] K. R. Kazmi and S. H. Rizvi, "Iterative approximation of a common solution of a split equilibrium problem, a variational inequality problem and a fixed point problem", Journal of the Egyptian Mathematical Society, vol. 21, no. 1, pp. 44-51, Apr. 2013, doi: 10.1016/j.joems.2012.10.009

[8] K. R. Kazmi and S. H. Rizvi, "An iterative method for split variational inclusion problem and fixed point problem for a nonexpansive mapping", Optimization letters, vol. 8, no. 3, pp. 1113-1124, Mar. 2013, doi: 10.1007/s11590-013-0629-2

[9] K. R. Kazmi and R. Ali, "Common solution to an equilibrium problem and a fixed point problem for an asymptotically quasi- $\phi$-nonexpansive mapping in intermediate sense", Revista de la Real Academia de Ciencias Exactas, Físicas y Naturales. Serie A. Matemáticas, vol. 111, no. 3, pp. 877-889, Sep. 2016, doi: 10.1007/s13398-016-0331-1

[10] S. A. Khan and J.-W. Chen, "Gap functions and error bounds for generalized mixed vector equilibrium problems", Journal of optimization theory and applications, vol. 166, no. 3, pp. 767-776, Nov. 2014, doi: 10.1007/s10957-014-0683-7 
[11] F. Kohsaka and W. Takahashi, "Existence and approximation of fixed points of firmly nonexpansive-type mappings in Banach spaces", SIAM journal on optimization, vol. 19, no. 2, pp. 824-835, 2008, doi: $10.1137 / 070688717$

[12] H. B. Liu, "Convergence theorems for a finite family of nonspreading and nonexpansive set-valued mappings and nonexpansive setvalued mappings and equilibrium problems with application", Theoretical mathematics \& applications, vol. 3, no. 3, pp. 49-61, 2013. [On line]. Available: https://bit.ly/2zAH72p

[13] W. R. Mann, "Mean value methods in iteration", Proceedings of the American Mathematical Society, vol. 4, no. 3, pp. 506-506, Mar. 1953, doi: 10.1090/S0002-9939-1953-0054846-3

[14] K. Nakajo and W. Takahashi, "Strong convergence theorems for nonexpansive mappings and nonexpansive semigroups", Journal of mathematical analysis and applications, vol. 279, no. 2, pp. 372-379, Mar. 2003, doi: 10.1016/S0022-247X(02)00458-4

[15] S. Suantai, P. Cholamjiak, Y. J. Cho, and W. Cholamjiak, "On solving split equilibrium problems and fixed point problems of nonspreading multivalued mappings in Hilbert spaces", Fixed point theory and applications, vol. 2016, no. 1, Mar. 2016, doi: 10.1186/s13663-016-0509-4

[16] R. Suparatulatorn, S. Suantai, and W. Cholamjiak, "Hybrid methods for a finite family of G-nonexpansive mappings in Hilbert spaces endowed with graphs", AKCE international journal of graphs and combinatorics, vol. 14, no. 2, pp. 101-111, Aug. 2017, doi: 10.1016/j.akcej.2017.01.001

[17] S. Suwannaut and A. Kangtunyakarn, "The combination of the set of solutions of equilibrium problem for convergence theorem of the set of fixed points of strictly pseudo-contractive mappings and variational inequalities problem", Fixed point theory and applications, vol. 2013, no. 1, Nov. 2013, doi: 10.1186/1687-1812-2013-291

[18] S. Suwannaut and A. Kangtunyakarn, "Convergence analysis for the equilibrium problems with numerical results", Fixed point theory and applications, vol. 2014, no. 1, Art ID. 167, Aug. 2014, doi: 10.1186/16871812-2014-167

[19] A. Tada and W. Takahashi, "Weak and strong convergence theorems for a nonexpansive mapping and an equilibrium problem", Journal of optimization theory and applications, vol. 133, no. 3, pp. 359-370, May 2007, doi: 10.1007/s10957-007-9187-z

[20] F. Usman and S. A. Khan, "A generalized mixed vector variational-like inequality problem", Nonlinear analysis: theory, methods \& applications, vol. 71, no. 11, pp. 5354-5362, Dec. 2009, doi: 10.1016/j.na.2009.04.023 